BATISTA MAV; BEZERRANETO F; SILVA ML; AMBRÓSIO MMQ; CUNHA JLXL. 2016. Atributos de solo-planta e de produção de beterraba influenciados pela adubação com espécies da Caatinga. Horticultura Brasileira 34: 031-038. DOI - http://dx.doi.org/10.1590/S0102-053620160000100005

\title{
Atributos de solo-planta e de produção de beterraba influenciados pela adubação com espécies da Caatinga
}

\author{
Marcos AV Batista ${ }^{1}$; Francisco Bezerra Neto ${ }^{2}$; Maiele L Silva ${ }^{3}$; Márcia MQ Ambrósio ${ }^{2}$; Jorge LXL Cunha ${ }^{4}$ \\ ${ }^{1}$ Instituto Federal de Educação, Ciência e Tecnologia do Ceará, Iguatu-CE, Brasil; batistamar@ig.com.br; ${ }^{2}$ UFERSA, Mossoró-RN, Bra- \\ sil; bezerra@ufersa.edu.br; marciamichelle@ufersa.edu.br; ${ }^{3} \mathrm{UEMS}$, Aquidauana-MS, Brasil; maiele_engenharia@yahoo.com.br; ${ }^{4} \mathrm{UFAL}$, \\ Maceió-AL, Brasil; jorge.cunha.xavier@gmail.com
}

\section{RESUMO}

Plantas da vegetação espontânea do bioma Caatinga têm sido usadas como adubo verde nos sistemas de produção de hortaliças na região Nordeste do Brasil com o intuito de aumentar a produtividade das oleráceas e melhorar a exploração do meio ambiente. O presente trabalho foi realizado com o objetivo de avaliar o efeito de três espécies espontâneas da Caatinga como adubo verde em diferentes quantidades de biomassa nos atributos químicos do solo-planta e na produtividade da beterraba. O delineamento experimental foi em blocos completos casualizados com três repetições, sendo os tratamentos compostos de três espécies espontâneas da Caatinga: jitirana (Merremia aegyptia); mata-pasto (Senna uniflora) e flor-de-seda (Calotropis procera) utilizadas em cinco quantidades de biomassa $(5,4 ; 8,8 ; 12,2 ; 15,6$ e 21,0 t/ha em base seca) incorporadas ao solo. As características avaliadas no solo foram teores de matéria orgânica, alumínio, macronutrientes, $\mathrm{pH}$ e número de unidades formadoras de colônia (UFC) de bactérias, fungos e actinomicetos após a colheita; na planta foram avaliados os teores de macronutrientes na folha diagnóstica, produtividade total e comercial de raízes, massa seca de raízes e produtividade classificada de raízes. De modo geral, pode-se concluir que a adubação verde com as espécies espontâneas da Caatinga (jitirana, mata-pasto e flor-de-seda), proporcionou melhoria nos atributos químicos do solo e das plantas de beterraba. Os adubos verdes provenientes das espécies jitirana e flor-de-seda foram aqueles que proporcionaram o melhor desempenho produtivo da beterraba, com valores médios de produtividade total e comercial de 17,57; 15,39 e 18,74 e 16,33 t/ha, respectivamente. A adição ao solo de 21,0 t/ha de biomassa dos adubos verdes propiciou as maiores produtividades total $(21,94 \mathrm{t} / \mathrm{ha})$ e comercial $(20,58 \mathrm{t} / \mathrm{ha})$ de beterraba.

Palavras-chave: Beta vulgaris, Merremia aegyptia, Senna uniflora, Calotropis procera, eficiência agronômica.

\begin{abstract}
Soil-plant attributes and beet production influenced by fertilization with species of Brazilian Caatinga

Plants of spontaneous vegetation of the Brazilian Caatinga bioma have been used as green manure in vegetable production systems in Northeastern Brazil with the aim of increasing the productivity of vegetables and improving the exploitation of the environment. The present work was carried out to evaluate the effect of three spontaneous species of the Brazilian Caatinga as green manure in different amounts of biomass in the chemical attributes of soil-plant and in the productivity of beet. The experimental design was of randomized complete blocks with three replications, the treatments being composed of three spontaneous species of the Brazilian Caatinga: hairy woodrose (Merremia aegyptia); oneleaf senna (Senna uniflora) and roostertree (Calotropis procera) used in five amounts of dry biomass $(5.4,8.8,12.2,15.6$ and $21.0 \mathrm{t} / \mathrm{ha}$ in dry basis) incorporated into the soil. The characteristics evaluated in the soil were the contents of organic matter, aluminum, macronutrients, $\mathrm{pH}$ and number of colony-forming units (CFU) in the soil of bacteria, fungi and actinomycetes after the harvest. From the plants we evaluated the macronutrient contents in the diagnostic leaf, besides the total and marketable productivity of roots, root dry mass and classified productivity of roots. In general, it can be concluded that the green manure using spontaneous species of the Caatinga biome (hairy woodrose, oneleaf senna and roostertree), provided improvement in the soil chemical properties and beet plants. The green manures obtained from the hairy woodrose and roostertree species were those that provided the best productive performance of beet, with average values of total and marketable productivity of 17.57 and $15.39 \mathrm{t} / \mathrm{ha}$, and 18.74 and $16.33 \mathrm{t} / \mathrm{ha}$, respectively. The addition to soil of $21.0 \mathrm{t} /$ ha of green manure biomass provided the greatest total $(21.94 \mathrm{t} / \mathrm{ha})$ and marketable yield (20.58 $\mathrm{t} / \mathrm{ha})$ of beet.
\end{abstract}

Keywords: Beta vulgaris, Merremia aegyptia, Senna uniflora, Calotropis procera, agronomic efficiency.

(Recebido para publicação em 15 de abril de 2014; aceito em 10 de agosto de 2015) (Received on April 15, 2014; accepted on August 10, 2015)

$\mathrm{A}$ beterraba é uma das principais hortaliças cultivadas no Brasil (Tivelli et al., 2011). A sua área plantada no Brasil é estimada em mais de 10.000 hectares com produção anual de 300 mil toneladas e produtividade média entre 20 e 30 t/ha (Matos et al., 2012). No Brasil são em torno de 21.937 unidades produtoras, sendo 2.693 unidades na região Nordeste e 32 unidades de pro- dução no Rio Grande no Norte (IBGE, 2009).

Esta hortaliça é bastante exigente em termos nutricionais e tem sido cultivada de forma convencional, com 
uso intensivo de fertilizantes minerais e agrotóxicos, afetando o meio ambiente além de tornar o sistema de produção mais caro. Em função disso, novas alternativas têm surgido para minimizar ou eliminar o uso de fertilizantes minerais. Uma das alternativas viáveis para suprir a beterraba com nutrientes é a utilização da adubação verde. É uma prática onde se incorpora ao solo plantas com elevada produção de biomassa, ricas em nutrientes, podendo melhorá-lo, física, química e biologicamente, além de proporcionar a conservação ou o aumento da fertilidade. Esta prática, além de melhorar a fertilidade, aumenta o teor de matéria orgânica, diminui os índices de erosão, favorece a retenção de água no solo, aumenta a atividade da microbiota do solo aumentando a disponibilidade de nutrientes e reduz a quantidade de plantas invasoras (Graham \& Haynes, 2006).

A atividade da microbiota do solo é responsável pela decomposição dos compostos orgânicos, pela ciclagem de nutrientes e pelo fluxo de energia do solo, e a biomassa microbiana e sua atividade têm sido apontadas como as características mais sensíveis às alterações na qualidade do solo, causadas por mudanças de uso e práticas de manejo (Trannin et al., 2007). Esta biomassa é o compartimento da matéria orgânica do solo diretamente influenciado por fatores bióticos e abióticos, de tal forma que respostas a mudanças nos sistemas de uso e manejo do solo podem ser detectáveis muito mais rapidamente pela biomassa microbiana e seus metabólitos do que nos teores de carbono do solo, principalmente devido ao tempo de ciclagem da matéria orgânica (Gama-Rodrigues et al., 2005).

O uso de espécies espontâneas do bioma Caatinga como adubo verde tem-se tornado uma alternativa importante de produção agrícola para alcançar o equilíbrio entre o aumento na produtividade das culturas e a exploração do meio ambiente. Essas espécies apresentam alta produção de fitomassa, rápido crescimento e estreita relação $\mathrm{C} / \mathrm{N}$, além de serem adaptadas às condições edafoclimáticas da região (Linhares et al., 2012).

O semiárido nordestino apresenta diversas plantas espontâneas do bioma com várias características que melhoram o solo, e que através de um manejo adequado estão sendo usadas eficientemente no cultivo de hortaliças (Góes et al., 2014; Souza et al., 2015). Entre estas plantas, está a jitirana (Merremia aegyptia), o mata-pasto (Senna uniflora) e a flor-de-seda (Calotropis procera). Bezerra Neto et al. (2011), trabalhando com diferentes quantidades de biomassa e tempo de decomposição de jitirana como adubo verde, observaram aumento de $28 \%$ na produtividade de alface em função de quantidades crescentes de jitirana incorporadas ao solo. Por outro lado, Linhares et al. (2009), trabalhando com mata-pasto em rúcula, observaram incrementos na altura de plantas, número de folhas por planta e nos rendimentos de massa verde e seca com o uso dessa espécie. Por sua vez, Silva et al. (2013), avaliando quantidades e diferentes proporções de parcelamentos de flor-de-seda na produção de cenoura, observaram que a quantidade de $45 \mathrm{t}$ / ha de flor-de-seda incorporada ao solo no parcelamento de 30\% 15 dias antes da semeadura $+70 \% 30$ dias depois da semeadura, proporcionaram maior produtividade da cenoura.

O objetivo deste trabalho foi avaliar o efeito de três espécies espontâneas do bioma Caatinga como adubo verde em diferentes quantidades de biomassa nos atributos químicos de solo-planta e na produtividade da beterraba.

\section{MATERIAL E MÉTODOS}

O trabalho foi conduzido de dezembro de 2009 a fevereiro de 2010, em campo na Fazenda Experimental Rafael Fernandes, da Universidade Federal Rural do Semi-Árido, localizada no distrito de Alagoinha, distante $20 \mathrm{~km}$ da sede do município de Mossoró ( $5^{\circ} 11^{\prime} \mathrm{S}$, $37^{\circ} 20^{\prime} \mathrm{O}, 18 \mathrm{~m}$ de altitude). Durante o período experimental, a temperatura média máxima esteve entre 33,5 e $34,4^{\circ} \mathrm{C}$ e a média mínima entre 23,2 e $24,7^{\circ} \mathrm{C}$, registrando-se uma umidade relativa média do ar entre 39,45 e $84,17 \%$, sem ocorrência de precipitação pluviométrica. O solo da área experimental foi classificado como Latossolo Vermelho Amarelo Distrófico. Amostras de solo da área experimental foram retiradas para determinação de seus atributos químicos (Tabela 1).

O delineamento experimental foi em blocos completos casualizados com os tratamentos arranjados em esquema fatorial $3 \times 5$, com três repetições. Os tratamentos consistiram da combinação de três espécies (jitirana, mata-pasto e flor-de-seda) com cinco quantidades de biomassa incorporadas ao solo $(5,4 ; 8,8$; 12,$2 ; 15,6$ e $21,0 \mathrm{t} / \mathrm{ha}$ em base seca). Cada parcela constou de seis fileiras de plantas espaçadas de $20 \times 10 \mathrm{~cm}$, com área total de $1,44 \mathrm{~m}^{2} \mathrm{e}$ área útil de 0,80 $\mathrm{m}^{2}$, sendo as linhas laterais e as plantas de cabeceira de cada linha da área útil considerada bordaduras. Empregou-se a cultivar de beterraba Early Wonder TT, com raiz globular, folhas com altura de 45-55 cm e diâmetro comercial de 6-8 $\mathrm{cm}$, recomendada para as condições semiáridas do nordeste brasileiro.

Os adubos verdes foram coletados da vegetação da Caatinga, triturados em pedaços de $2-3 \mathrm{~cm}$, secos e colocados para secar em temperatura ambiente até atingirem ponto de fenação (em torno de quatro a cinco dias). Amostras de cada espécie foram levadas à estufa com circulação de ar a $65^{\circ} \mathrm{C}$ para determinação do teor de umidade (obtendo-se os seguintes valores: $10 ; 9,15$ e $7,5 \%$ para jitirana, mata-pasto e flor-de-seda, respectivamente), e após moagem do material, foram feitas análises químicas de nutrientes (Tabela 2).

O preparo do solo da área experimental consistiu de uma gradagem seguida de levantamento dos canteiros. A incorporação dos adubos verdes nas parcelas foi realizada em 01 de dezembro de 2009. Após 14 dias da incorporação dos adubos, procedeu-se à semeadura da beterraba (14/12/2009), diretamente nos canteiros, em covas de $3,0 \mathrm{~cm}$ de profundidade. Foram colocadas quatro sementes por cova, fazendo-se o desbaste aos 14 dias após a semeadura, deixando-se uma planta por cova no espaçamento de $20 \mathrm{~cm}$ entre fileiras e 5 $\mathrm{cm}$ entre plantas.

As irrigações foram diárias, por micro-aspersão, em dois turnos de rega de manhã e tarde, fornecendo-se uma lâmina de água estimada de aproximadamente $8,0 \mathrm{~mm} / \mathrm{dia}$. Como tratos 
culturais foram realizados uma capina manual e uma amontoa e controle de pragas e doenças.

Em cada parcela foram coletadas 20 folhas recém-maduras, quando as plantas se encontravam com 46 dias (28/01/2010), aproximadamente 2/3 do ciclo, para a determinação dos macronutrientes nas plantas pela digestão sulfúrica e nítrico-perclórica.

A colheita da beterraba foi realizada aos setenta dias após a semeadura (23/02/2010), avaliando-se a produtividade total (massa da matéria fresca total das raízes das plantas da área útil), a produtividade comercial (massa da matéria fresca das raízes das plantas da área útil livres de rachaduras, nematóides e danos mecânicos), a massa seca de raízes tomada em amostras de 10 plantas e a produtividade classificada de raízes, determinada através da classificação do diâmetro das raízes (DR) em extra $(4<\mathrm{DR}<5 \mathrm{~cm})$; extra $\mathrm{A}(5 \leq \mathrm{DR}<6$ $\mathrm{cm})$; extra AA $(6 \leq \mathrm{DR}<7 \mathrm{~cm})$ e graúdas (DR $>7 \mathrm{~cm})$, sendo consideradas refugo todas as raízes danificadas, rachadas e menores de $4 \mathrm{~cm}$ de diâmetro.

Ao término do experimento foram coletadas amostras de terra $(0-20 \mathrm{~cm})$ para determinação de $\mathrm{P}, \mathrm{S}, \mathrm{K}, \mathrm{Ca}, \mathrm{Mg}$ e
$\mathrm{Na}$, matéria orgânica e pH (Tabela 1) e para quantificação dos microrganismos através de diluição seriada e plaqueamento em meios seletivos, mediante a técnica de contagem em placas de Petri. Para o isolamento de bactérias foi empregado o meio de cultura Nutriente Agar (NA) e as diluições de $10^{-5}$ e $10^{-6}$. Para o isolamento de actinomicetes foi empregado o Meio Amido caseína (AC) e as diluições $10^{-3}$ e $10^{-4}$. No isolamento de fungos foi empregado o Meio de Martin e as diluições $10^{-1}$ e $10^{-2}$. Foram feitas três repetições para cada combinação meio-diluição e as placas foram mantidas em estufa incubadora tipo BOD (demanda biológica de oxigênio) a $28 \pm 2{ }^{\circ} \mathrm{C}$. O número de colônias por placa foi contado após três dias (bactérias) e cinco dias (actinomicetos e fungos).

As pressuposições da normalidade, homogeneidade e aditividade dos erros das análises de variâncias no delineamento em blocos casualizados em esquema fatorial das características avaliadas foram testadas através do aplicativo software SISVAR 3.01 (Ferreira, 2000) e satisfeitas. O procedimento de ajustamento de curvas de resposta para as quantidades de adubos incorporadas foi realizado através do software Table
Curve (Jandel Scientific, 1991). O teste de Tukey foi utilizado para comparar as médias entre as espécies espontâneas estudadas.

\section{RESULTADOS E DISCUSSÃO}

Não houve interação significativa entre as espécies espontâneas da Caatinga e as quantidades de biomassa utilizadas como adubo verde nos atributos químicos do solo depois da colheita da beterraba e no número de unidades formadoras de colônia (UFC) de bactérias, fungos e actinomicetos (Tabela 1). Isto significa que as espécies tiveram comportamentos semelhantes nas diferentes quantidades de biomassa incorporadas e vice-versa. No entanto, independentemente das quantidades incorporadas, não foram observadas diferenças significativas entre os valores médios dos atributos químicos entre as espécies, exceto no número de unidades formadoras de colônias (UFC) de bactérias e de fungos, com a espécie mata-pasto se sobressaindo das espécies jitirana e flor-de-seda (Tabela 1). Provavelmente, essa significância se deva às pequenas diferenças na composição química do

Tabela 1. Análises químicas do solo antes da incorporação dos adubos e depois da colheita da beterraba adubada com as espécies espontâneas, jitirana, mata-pasto e flor-de-seda e os valores médios de unidades formadoras de colônia no solo de bactérias, fungos e actinomicetos em solo cultivado com beterraba em diferentes quantidades de biomassa das espécies espontâneas incorporadas (chemical analyses of the soil before incorporation of fertilizers and after harvesting of beet fertilized with the spontaneous species, hairy woodrose; oneleaf senna and roostertree and the mean values, in the soil, of colony-forming units in the soil of bacteria, fungi and actinomycetes in soil cultivated with beet in different amounts of spontaneous species biomass incorporated). Mossoró, UFERSA, 2010.

\begin{tabular}{|c|c|c|c|c|c|c|c|c|c|}
\hline \multicolumn{10}{|c|}{ Antes da incorporação das espécies espontâneas } \\
\hline M.O. & \multirow{2}{*}{ pH } & \multirow{2}{*}{$\begin{array}{c}\mathbf{P}(\mathbf{m g} / \\
\left.\mathbf{d m}^{3}\right)\end{array}$} & $\mathbf{K}$ & $\mathbf{C a}$ & Mg & $\mathrm{Na}$ & $\mathbf{H}+\mathbf{A l}$ & \multirow{2}{*}{$\begin{array}{c}\mathrm{Al}\left(\mathrm{cmol}_{\mathbf{c}} /\right. \\
\left.\mathbf{d m}^{3}\right)\end{array}$} & \multirow{2}{*}{$\begin{array}{c}C E \\
(d S / m)\end{array}$} \\
\hline$(\mathrm{g} / \mathrm{kg})$ & & & \multicolumn{5}{|c|}{$\left(\mathrm{mmol} / \mathrm{dm}^{3}\right)$} & & \\
\hline 10,34 & 7,00 & 4,00 & 1,50 & 25,00 & 10,00 & 2,78 & 11,60 & 0,00 & 0,88 \\
\hline \multirow{3}{*}{$\begin{array}{l}\text { Espécies } \\
\text { espontâneas }\end{array}$} & \multicolumn{9}{|c|}{ Depois da colheita da beterraba adubada com as espécies espontâneas } \\
\hline & M.O. & $\mathbf{C}$ & $\mathbf{P}$ & $\mathbf{S}$ & $n \mathrm{n}$ & $\mathbf{K}$ & $\mathbf{C a}$ & Mg & $\mathbf{N a}$ \\
\hline & \multicolumn{2}{|c|}{$\left(\mathrm{g} / \mathrm{kg}^{1}\right)$} & \multicolumn{2}{|c|}{$\left(\mathrm{mg} / \mathrm{dm}^{3}\right)$} & pH & \multicolumn{4}{|c|}{$\left(\mathrm{mmol} / \mathrm{dm}^{3}\right)$} \\
\hline Jitirana & $7,87 \mathrm{a}$ & $4,57 \mathrm{a}$ & $4,60 \mathrm{a}$ & $1,94 \mathrm{a}$ & $8,20 \mathrm{a}$ & $1,37 \mathrm{a}$ & $65,30 \mathrm{a}$ & $23,30 \mathrm{a}$ & $2,91 \mathrm{a}$ \\
\hline Mata-pasto & $8,17 \mathrm{a}$ & $4,74 \mathrm{a}$ & $8,10 \mathrm{a}$ & $2,87 \mathrm{a}$ & $8,20 \mathrm{a}$ & $1,49 \mathrm{a}$ & $65,40 \mathrm{a}$ & $25,40 \mathrm{a}$ & $2,63 \mathrm{a}$ \\
\hline \multirow[t]{2}{*}{ Flor-de-seda } & $7,61 \mathrm{a}$ & $4,42 \mathrm{a}$ & $8,30 \mathrm{a}$ & $2,54 \mathrm{a}$ & $8,10 \mathrm{a}$ & $1,41 \mathrm{a}$ & $65,10 \mathrm{a}$ & $23,90 \mathrm{a}$ & $2,84 \mathrm{a}$ \\
\hline & \multicolumn{3}{|c|}{ UFC de bactérias (x 105) } & \multicolumn{3}{|c|}{ UFC de fungos (x 10²) } & \multicolumn{3}{|c|}{ UFC de actinomicetos $\left(x 1^{3}\right)$} \\
\hline Jitirana & \multicolumn{3}{|c|}{$26,2 \mathrm{~b}$} & \multicolumn{3}{|c|}{$19,7 \mathrm{~b}$} & \multicolumn{3}{|c|}{$22,6 \mathrm{a} *$} \\
\hline Mata-pasto & \multicolumn{3}{|c|}{$38,0 \mathrm{a}$} & \multicolumn{3}{|c|}{$22,4 \mathrm{a}$} & \multicolumn{3}{|c|}{$21,2 \mathrm{a}$} \\
\hline Flor-de-seda & \multicolumn{2}{|r|}{$29,4 \mathrm{~b}$} & & \multicolumn{3}{|c|}{$13,7 \mathrm{~b}$} & \multicolumn{3}{|c|}{$21,0 \mathrm{a}$} \\
\hline
\end{tabular}

*Médias seguidas pela mesma letra na coluna não diferem entre si pelo teste de Tukey ao nível de 5\% de probabilidade (means followed by the same letter in the column do not differ by Tukey test, $5 \%$ ). 
Tabela 2. Teores de macronutrientes dos adubos verdes e da folha diagnose da beterraba adubada com as espécies espontâneas, jitirana, mata-pasto e flor-de-seda (macronutrient contents of green manures and diagnosis leaf of beet fertilized with spontaneous species, hairy woodrose; oneleaf senna and roostertree). Mossoró, UFERSA, 2010.

\begin{tabular}{lccccccc}
\hline \multirow{2}{*}{ Espécies espontâneas } & $\mathbf{7}$ Teores de macronutrientes nos adubos verdes (g/kg) \\
\cline { 2 - 8 } & $\mathbf{N}$ & $\mathbf{P}$ & $\mathbf{K}$ & $\mathbf{C a}$ & $\mathbf{M g}$ & $\mathbf{S}$ & $\mathbf{C}: \mathbf{N}$ \\
\hline Jitirana & $19,76 \mathrm{a}$ & $3,79 \mathrm{a}$ & $34,28 \mathrm{a}$ & $8,93 \mathrm{a}$ & $5,00 \mathrm{a}$ & $1,30 \mathrm{a}$ & $25: 1$ \\
Mata-pasto & $16,87 \mathrm{a}$ & $4,11 \mathrm{a}$ & $15,63 \mathrm{a}$ & $18,81 \mathrm{a}$ & $2,60 \mathrm{a}$ & $1,50 \mathrm{a}$ & $36: 1$ \\
Flor-de-seda & $24,06 \mathrm{a}$ & $4,00 \mathrm{a}$ & $15,70 \mathrm{a}$ & $17,23 \mathrm{a}$ & $2,60 \mathrm{a}$ & $1,70 \mathrm{a}$ & $17: 1$ \\
\hline \multicolumn{7}{c}{ Teores de macronutrientes na folha diagnose (g/kg) } \\
\hline Jitirana & $27,41 \mathrm{a} *$ & $2,84 \mathrm{a}$ & $69,89 \mathrm{a}$ & $9,1 \mathrm{~b}$ & $9,0 \mathrm{~b}$ & $5,03 \mathrm{a}$ \\
Mata-pasto & $28,47 \mathrm{a}$ & $2,65 \mathrm{a}$ & $71,91 \mathrm{~b}$ & $10,0 \mathrm{a}$ & $9,3 \mathrm{ab}$ & $4,72 \mathrm{a}$ \\
Flor-de-seda & $27,32 \mathrm{a}$ & $2,98 \mathrm{a}$ & $69,92 \mathrm{ab}$ & $9,0 \mathrm{~b}$ & $10,0 \mathrm{a}$ & $5,03 \mathrm{a}$ \\
\hline
\end{tabular}

*Médias seguidas pela mesma letra na coluna não diferem entre si pelo teste de Tukey ao nível de $5 \%$ de probabilidade (means followed by the same letter in the column do not differ by Tukey test, $5 \%$ ).

Tabela 3. Produtividade total (PT), comercial (PC), massa seca de raízes (MSR), percentagem de raízes extra (E), raízes extra A (EA), raízes extra AA (EAA), raízes graúdas $(\mathrm{G})$ e raízes refugo $(\mathrm{R})$ de beterraba adubada com as espécies espontâneas, jitirana, mata-pasto e flor-de-seda (total productivity (PT), marketable productivity (PC), dry mass of roots (MSR), percentage of extra roots (E), extra roots A (EA), extra roots AA (EAA), great roots $(\mathrm{G})$ and disposal roots $(\mathrm{R})$ of beet fertilized with spontaneous, hairy woodrose; oneleaf senna and roostertree). Mossoró, UFERSA, 2010.

\begin{tabular}{|c|c|c|c|c|c|c|c|c|}
\hline \multirow{3}{*}{$\begin{array}{l}\text { Espécies } \\
\text { espontâneas }\end{array}$} & \multicolumn{3}{|c|}{ Produtividade } & \multicolumn{5}{|c|}{ Produtividade classificada } \\
\hline & PT & $\mathbf{P C}$ & \multirow{2}{*}{$\begin{array}{l}\text { MSR (g/ } \\
\text { planta) }\end{array}$} & $\mathbf{E}$ & EA & EAA & $\mathbf{G}$ & $\mathbf{R}$ \\
\hline & & & & \multicolumn{5}{|c|}{$(\%)$} \\
\hline Jitirana & $17,57 \mathrm{a}$ & $15,39 \mathrm{a}$ & $6,45 \mathrm{a}^{*}$ & $34,7 \mathrm{a}$ & $21,8 \mathrm{a}$ & $9,6 \mathrm{a}$ & $4,7 \mathrm{a}$ & $29,2 \mathrm{a}$ \\
\hline Mata-pasto & $15,26 \mathrm{~b}$ & $12,83 \mathrm{~b}$ & $5,89 \mathrm{a}$ & $36,5 \mathrm{a}$ & $19,3 \mathrm{a}$ & $8,2 \mathrm{a}$ & $2,3 \mathrm{a}$ & $33,7 \mathrm{a}$ \\
\hline Flor-de-seda & $18,74 \mathrm{a}$ & $16,33 \mathrm{a}$ & $6,55 \mathrm{a}$ & $28,5 \mathrm{a}$ & $20,9 \mathrm{a}$ & $12,1 \mathrm{a}$ & $7,7 \mathrm{a}$ & $30,8 \mathrm{a}$ \\
\hline
\end{tabular}

*Médias seguidas pela mesma letra na coluna não diferem entre si pelo teste de Tukey ao nível de 5\% de probabilidade (means followed by the same letter in the column do not differ by Tukey test, $5 \%$ ).

mata-pasto em relação as dos outros materiais. Sabe-se que a incorporação ao solo de qualquer material vegetal favorece a atividade microbiana, pois existe uma estreita relação entre matéria orgânica e a biomassa microbiana do solo. A aplicação de um resíduo orgânico no solo resulta em estímulos diferenciados aos microrganismos, devido a uma modificação direta ou indireta das características do meio, determinantes da qualidade, quantidade e atividade da população microbiana existente. Estes resultados são discordantes em parte dos reportados por Barroti \& Nahas (2000) onde não observaram diferenças na população microbiana total de fungos e bactérias em função das espécies (gramínea ou leguminosa), fontes de fósforo e calagem.

Os teores de carbono, matéria orgânica, potássio e enxofre de $5,28 \mathrm{~g} /$ $\mathrm{kg} ; 9,03 \mathrm{~g} / \mathrm{kg} ; 1,57 \mathrm{mg} / \mathrm{dm}^{3}$ e $2,95 \mathrm{mg} /$ $\mathrm{dm}^{3}$, aumentaram com as quantidades de biomassa dos adubos verdes (em um modelo polinomial) até as quantidades de 17,$81 ; 17,67 ; 13,72$ e 13,12 t/ha, respectivamente, decrescendo, em seguida, até a maior quantidade de adubo incorporada ao solo (Figuras 1A e 1B). Também foi observado um aumento da ordem de $6,81 \mathrm{mg} / \mathrm{dm}^{3}, 5,99$ e 6,23 $\mathrm{mmol} / \mathrm{cm}^{3}$ nos teores de fósforo, cálcio e magnésio entre a menor e a maior quantidade de biomassa dos adubos verdes adicionados ao solo, com valores máximos de $11,17 \mathrm{mg} / \mathrm{dm}^{3} ; 67,09$ e $28,23 \mathrm{mmol} / \mathrm{dm}^{3}$ registrados na maior quantidade dos adubos verdes $(21,00 \mathrm{t} /$ ha), (Figura 1C). Por outro lado, nenhuma equação de regressão foi possível ajustar para os teores de sódio em função das quantidades de biomassa dos adubos verdes (Figura 1D).

Ao término do cultivo da beterraba, os teores de $\mathrm{P}, \mathrm{K}, \mathrm{Ca}, \mathrm{Mg}$ e Na no solo (Tabela 1) estiveram, dentro da faixa ótima desses elementos, que são de
4,60-8,30 mg/dm 3 para $\mathrm{P} ; 1,37-1,49$ $\mathrm{mmol}_{\mathrm{c}} / \mathrm{dm}^{3}$ para K; 65, 10-65,40 $\mathrm{mmol}_{\mathrm{c}} /$ $\mathrm{dm}^{3}$ para Ca; 23,30-25,40 $\mathrm{mmol} / \mathrm{dm}^{3}$ para Mg e de 2,63-2,91 $\mathrm{mmol}_{\mathrm{c}} / \mathrm{dm}^{\mathrm{c}}$ para $\mathrm{Na}$ (Cavalcanti, 1998). Com relação ao $\mathrm{pH}$ no solo obteve-se um valor entre 8,10 e 8,20 (característico de um solo alcalino). Como a fertilização do solo foi feita com adubo verde, o aumento no $\mathrm{pH}$ causa quase nenhuma desvantagem nos teores dos macronutrientes quando comparado com os fertilizantes químicos. Antes do cultivo da beterraba esse solo estava com $\mathrm{pH}$ neutro. Diante disso, pode-se registrar que a adubação do solo com as espécies espontâneas melhorou a fertilidade do mesmo, com melhora dos teores dos nutrientes $\mathrm{P}, \mathrm{K}$, $\mathrm{Ca}, \mathrm{Mg}$ e $\mathrm{Na}$ (Tabela 1). Nessa faixa de $\mathrm{pH}$, os teores de cálcio, magnésio e potássio permaneceram quase inalterados. Com relação ao nitrogênio, poderíamos ter perdas se estivéssemos usando fertilizantes químicos, pois em 


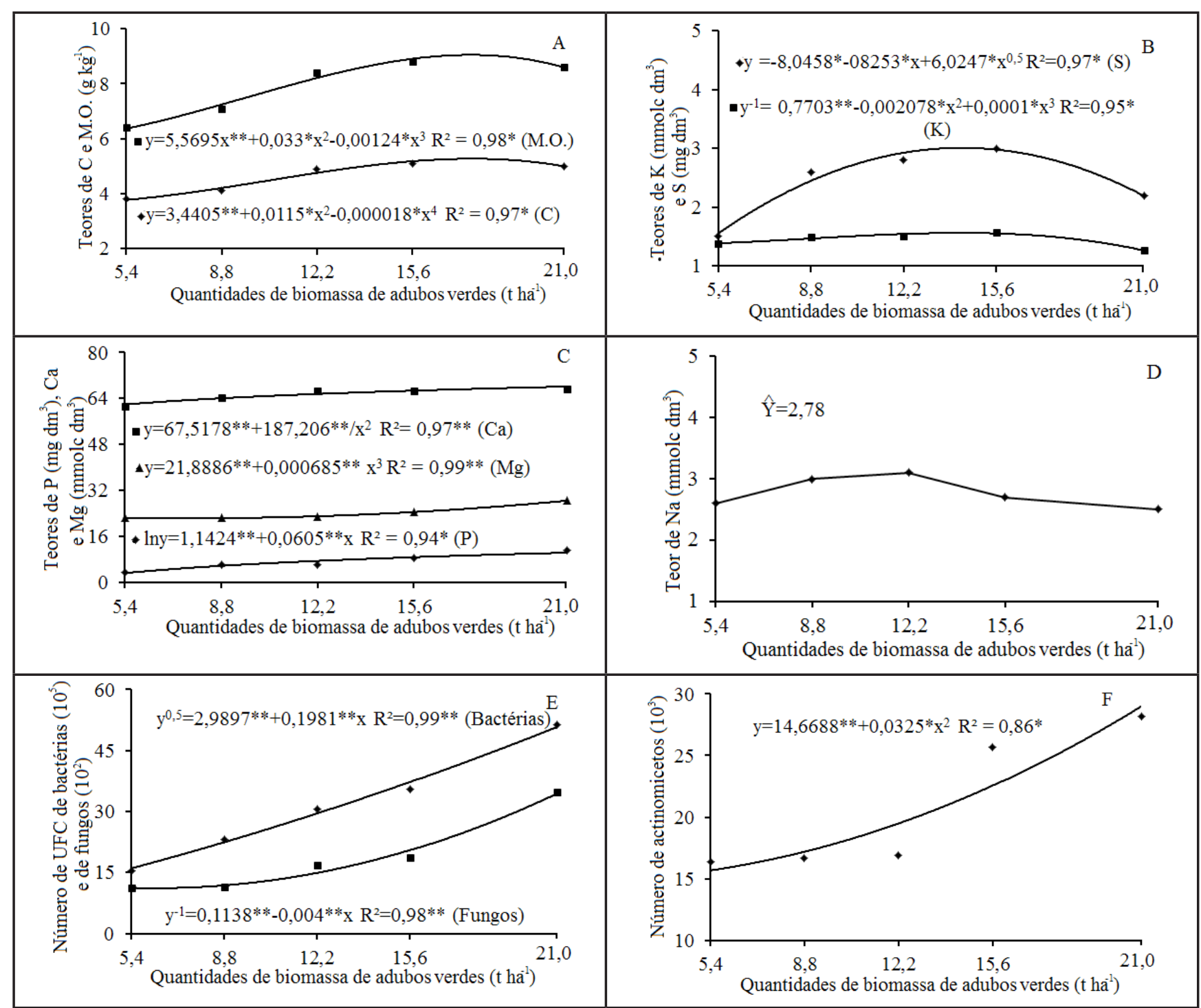

Figura 1. Teores de carbono (C), matéria orgânica (M.O.), potássio (K), enxofre (S), fósforo (P), cálcio (Ca), magnésio (Mg), sódio (Na), número de unidades formadoras de colônias (UFC) de bactérias, fungos e de actinomicetos em solo cultivado com beterraba adubada com diferentes espécies espontâneas em diferentes quantidades de biomassa dessas espécies incorporadas ao solo \{contents of carbon (C), organic matter (M.O.), potassium (K), sulfur (S), phosphorus (P), calcium (Ca), magnesium (Mg), sodium (Na), number of colony-forming units (UFC) of bacteria, fungi and actinomycetes in soil cultivated with beet fertilized with different spontaneous species in different amounts of biomass incorporated into the soil\}. Mossoró, UFERSA, 2010.

solos alcalinos ou com $\mathrm{pH}$ acima de 7,0 , qualquer fertilizante nitrogenado que contém $\mathrm{N}$ amoniacal está sujeito a perdas de amônia por volatilização. Com relação ao fósforo, o aumento de $\mathrm{pH}$ de 7,0 para 8,0 provoca uma diminuição da presença de $\mathrm{H}_{2} \mathrm{PO}_{4}^{-}$em relação à forma $\mathrm{HPO}_{4}^{2-}$, preferencialmente absorvida, mas, ambas são absorvidas pela planta (Novais et al., 2007). Aumento de $\mathrm{pH}$, provoca aumento na disponibilidade de enxofre em função tanto do aumento da sua desorção, quanto pela redução de sua adsorção (Casagrande et al., 2003).

Com relação ao número de unida- des formadoras de colônia (UFC) foi registrado um aumento ascendente no número de UFC de bactérias, fungos e actinomicetos com as quantidades de biomassa dos adubos verdes incorporadas (Figuras 1E e 1F) da ordem de $34,64 \times 10^{5} ; 23,95 \times 10^{2}$ e $13,39 \times 10^{3}$, respectivamente, entre a menor e maior quantidade de biomassa adicionada ao solo. Os valores máximos dessas variáveis $\left(51,12 \times 10^{5}\right.$ para bactérias, $34,82 \times 10^{2}$ para fungos e $29,01 \times 10^{3}$ para actinomicetos) foram obtidos na quantidade de biomassa incorporada de 21,00 t/ha dos adubos verdes (Figuras
1E e 1F). No geral, o aumento destes microrganismos no solo, seja quantitativa ou qualitativamente pode apresentar grande importância, pois os mesmos contribuem para o crescimento das plantas e para o controle de fitopatógenos. Esse aumento no número de UFC, possivelmente, se deva à decomposição do material vegetal no solo, que induz à atividade de alguns microrganismos, como bactérias e actinomicetos, uma vez que, a decomposição desses materiais serve como fonte de macronutrientes e micronutrientes, hormônios, aminoácidos e outros para os microrganismos 


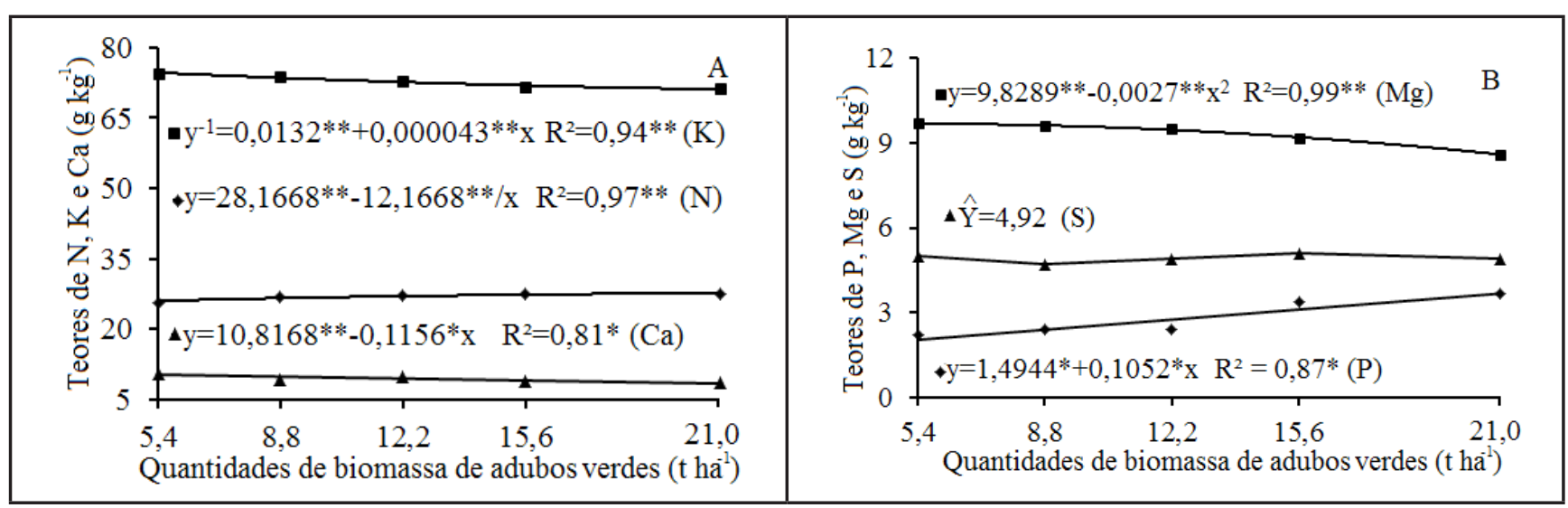

Figura 2. Teores de nitrogênio $(\mathrm{N})$, potássio $(\mathrm{K})$, cálcio $(\mathrm{Ca})$, fósforo $(\mathrm{P})$, magnésio $(\mathrm{Mg})$ e enxofre $(\mathrm{S})$ na folha diagnose da beterraba adubada com diferentes espécies espontâneas em diferentes quantidades de biomassa dessas espécies incorporadas ao solo \{contents of nitrogen $(\mathrm{N})$, potassium $(\mathrm{K})$, calcium $(\mathrm{Ca})$, phosphorus $(\mathrm{P})$, magnesium $(\mathrm{Mg})$ and sulfur $(\mathrm{S})$ in the diagnosis leaf of beet fertilized with different spontaneous species in different amounts of biomass incorporated into the soil\}. Mossoró, UFERSA, 2010.

(Bertiol \& Ghini, 2005). As bactérias e os actinomicetos desempenham um papel importante como promotores de crescimento de plantas, pela ação direta por meio da solubilização de nutrientes do substrato, produção de substâncias reguladoras de crescimento de plantas e pela ação indireta, por meio do controle de patógenos que limitam o crescimento das plantas (Cao et al., 2004).

Esses microrganismos são considerados de grande importância na agricultura por atuarem na fertilidade do solo realizando funções como: decomposição da matéria orgânica, principalmente dos compostos mais complexos, mineralização de nutrientes, solubilização dos fosfatos, nitrificação, fixação do dinitrogênio em não leguminosa e também atuando na proteção de plantas contra patógenos (Schippers et al., 1987).

A biomassa microbiana é um dos componentes que controlam as funções chaves no solo, como a decomposição e o acúmulo de matéria orgânica, ou transformações envolvendo os nutrientes minerais. Ela representa uma reserva considerável de nutrientes, os quais são continuamente assimilados durante os ciclos de crescimento dos diferentes organismos que compõem o ecossistema (Araújo \& Monteiro, 2007).

Não se observou diferenças significativas nos teores dos macronutrientes das espécies espontâneas da Caatinga antes da incorporação ao solo (Tabela 2). Durante o ciclo da beterraba, os teores dos macronutrientes nas folhas diagnose proporcionados pela adubação com essas espécies (Tabela 2) estiveram dentro das faixas adequadas recomendadas para a beterraba que são de $2-4 \mathrm{~g} / \mathrm{kg}$ para $\mathrm{P} ; 20-40 \mathrm{~g} / \mathrm{kg}$ para $\mathrm{K} ; 3-8 \mathrm{~g} / \mathrm{kg}$ para $\mathrm{Mg}$ e 2-4 g/kg para S. Os teores de $\mathrm{N}$ nas folhas diagnose das três espécies estiveram muito próximo do limite mínimo recomendado (30-50 g/ $/ \mathrm{kg}$ ) e os teores de Ca estiveram abaixo dos recomendados para a beterraba que são de $25-35 \mathrm{~g} / \mathrm{kg}$ (Faquin \& Andrade, 2004).

Não houve interação significativa entre as espécies espontâneas e as quantidades de biomassa utilizadas como adubo verde nos teores de macronutrientes da folha diagnose da beterraba (Tabela 2). No entanto, diferenças significativas foram observadas apenas nos teores $\mathrm{K}, \mathrm{Ca}$ e $\mathrm{Mg}$, entre as espécies, com os teores de $\mathrm{K}$ e Ca no mata-pasto sobressaindo-se dos teores da jitirana e da flor-de-seda, e o teor de Mg na flor-de-seda destacando-se dos teores da jitirana e do mata-pasto (Tabela 2).

Os teores de $\mathrm{N}$ aumentaram com as quantidades de biomassa dos adubos verdes de forma ascendente entre a menor e a maior quantidade de biomassa dos adubos adicionados ao solo, com valor máximo de $27,55 \mathrm{~g} / \mathrm{kg}$ registrado na maior quantidade dos adubos verdes $(21,00 \mathrm{t} / \mathrm{ha})$, (Figura 2A). Por outro lado, os teores de $\mathrm{K}$ e $\mathrm{Ca}$ decresceram de forma linear com as quantidades de biomassa dos adubos, alcançando os valores máximos de 74,40 e 10,19 g/kg na quantidade de biomassa de 5,40 t/ ha (Figura 2A). Silva \& Correia (2014) avaliaram a produtividade da beterraba utilizando crotalária como fornecedora de nitrogênio, substituindo parcialmente ou totalmente a adubação química nitrogenada e não encontraram diferença significativa entre os tratamentos. Os mesmos atribuíram esse resultado ao pouco tempo de incorporação da crotalária ao solo, o que não permitiu a sua decomposição.

Os teores de $\mathrm{P}$ aumentaram com as quantidades de biomassa dos adubos verdes de forma ascendente entre a menor e a maior quantidade de biomassa dos adubos adicionados ao solo, com valor máximo de $3,70 \mathrm{~g} / \mathrm{kg}$ registrado na maior quantidade dos adubos $(21,00$ t/ha), (Figura 2B). Comportamento inverso foi registrado com os teores de $\mathrm{Mg}$, decrescendo de forma linear com as quantidades de biomassa dos adubos, alcançando o valor máximo de $9,75 \mathrm{~g} /$ kg na quantidade de biomassa de 5,40 t/ha. Nenhuma equação de regressão foi possível ajustar para os teores de enxofre em função das quantidades de biomassa dos adubos verdes (Figura 2B). Não foi encontrado na literatura trabalho que registrasse os teores dos macronutrientes em função de diferentes quantidades de adubo verde em beterraba. No entanto, teores de $\mathrm{P}$ em folhas de rabanete ascenderam com o aumento das quantidades de adubos verdes, comportamento esse 


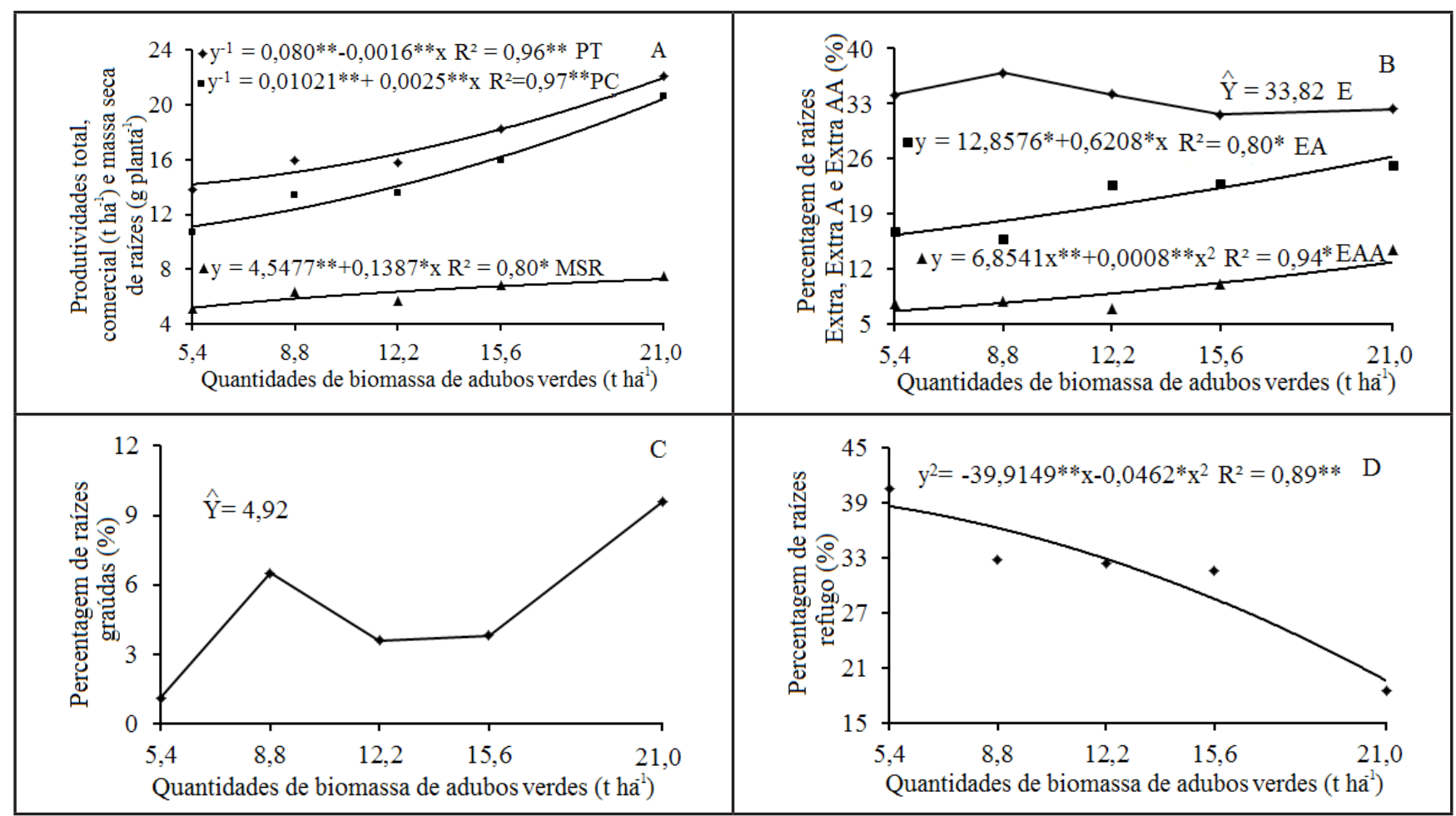

Figura 3. Produtividades total (PT), comercial (PC) e massa seca de raízes (MSR), percentagens de raízes extra (E), extra A (EA), extra AA (EAA), percentagens de raízes graúdas e refugo de beterraba adubada com diferentes espécies espontâneas em diferentes quantidades de biomassa dessas espécies incorporadas ao solo \{total productivity (PT), marketable productivity (PC), dry mass of roots (MSR), percentages of extra roots (E), extra A roots (EA), extra AA roots (EAA), percentage of great roots and disposal roots of beet fertilized with spontaneous, hairy woodrose, oneleaf senna and roostertree\}. Mossoró, UFERSA, 2010.

semelhante aos observados nas raízes de beterraba (Batista et al., 2013). Por outro lado, esses mesmos autores registraram também comportamento diferente nos teores de $\mathrm{K}$ dos observados nessa pesquisa.

Não houve interação significativa entre as quantidades de adubo verde incorporadas ao solo e as diferentes espécies desses adubos na produtividade total, comercial, massa seca de raízes e produtividade classificada (Tabela 3, Figuras 3A a 3D). No entanto, diferenças significativas entre as espécies foram observadas apenas nas produtividades total e comercial, com os valores médios da flor-de-seda e jitirana destacando-se frente ao mata pasto, embora estatisticamente semelhantes entre si (Tabela 3). $\mathrm{O}$ bom desempenho da beterraba com a flor-de-seda e jitirana parcialmente se deve ao fato dessas espécies apresentarem valores mais altos de nutrientes. A taxa de decomposição dos materiais orgânicos é controlada pelas suas características qualitativas, principalmente pela relação $\mathrm{C} / \mathrm{N}$ (Torres \& Pereira,
2008), que no caso da jitirana foi de $25: 1$, na flor-de-seda de 17:1 e no mata pasto de $36: 1$.

Um aumento nas produtividades total e comercial e na massa seca de raízes da beterraba foi registrado com as quantidades crescentes de biomassa dos adubos verdes entre a menor e a maior quantidade de biomassa desses adubos adicionados ao solo, com valores máximos de 21,94 e 20,58 t/ha e de 7,46 $\mathrm{g} /$ planta registrados na maior quantidade de biomassa dos adubos adicionados ao solo (21,00 t/ha), (Figura 3A).

Este comportamento crescente nessas variáveis pode ser explicado, em parte, pelos resultados de quantificação de bactérias, fungos e actinomicetos, que também apresentou esse comportamento. Em condições ideais, a microbiota do solo permite que os nutrientes sejam, gradualmente, liberados para a nutrição das plantas sem perdas por lixiviação. A diminuição da microbiota do solo prejudica a fixação temporária dos nutrientes, incrementando suas perdas e resultando no empobrecimento do solo.
Por outro lado, pode também ser devido aos aumentos crescentes da matéria orgânica e do fósforo com o aumento das quantidades de biomassa incorporadas. O aumento do teor de matéria orgânica foi de 33\% em relação à menor quantidade aplicada.

Não foi possível ajustar equação de regressão para as percentagens de raízes extras e graúdas em função das quantidades de biomassa incorporadas ao solo (Figuras 3B e 3C). Um aumento nas percentagens de raízes extra $\mathrm{A}$ e extra AA foi registrado com as quantidades crescentes de biomassa dos adubos verdes entre a menor e a maior quantidade de biomassa adicionada ao solo, com valores máximos de 25,89 e $14,24 \%$ registrados na maior quantidade de biomassa dos adubos verdes $(21,00$ t/ha), (Figura 3B).

Por outro lado, a percentagem de raízes refugo diminuiu com o aumento nas quantidades de biomassa dos adubos incorporados, com o valor máximo registrado na menor quantidade de biomassa dos adubos verdes $\left(5,4 \mathrm{t} / \mathrm{ha}^{-1}\right)$, 
(Figura 3D).

De modo geral, pode-se concluir que a adubação verde com jitirana, mata-pasto e flor-de-seda, proporcionou melhoria nos atributos químicos do solo e das plantas de beterraba. Entre as espécies estudadas, o mata-pasto se diferenciou das demais no número de unidades formadoras de colônias (UFC) de bactérias e fungos do solo. Aumento no número de UFC dos microrganismos analisados foi registrado com as quantidades crescentes de biomassa dos adubos incorporados. As maiores produtividades total e comercial e massa seca da parte aérea de beterraba foram obtidas com a adição ao solo de 21,0 $\mathrm{t} /$ ha de biomassa dos adubos verdes. A produtividade classificada de raízes de beterraba não foi influenciada pela incorporação da biomassa das espécies espontâneas. As maiores percentagens de raízes extra A e extra AA foram obtidas também com a incorporação de 21,0 t/ha de biomassa dos adubos verdes. Houve um decréscimo na percentagem de raízes refugo com as crescentes quantidades de biomassa dos adubos verdes.

\section{REFERÊNCIAS}

ARAÚJO ASF; MONTEIRO RTR. 2007. Indicadores biológicos de qualidade do solo. Uberlândia. Bioscience Journal 23: 66-75.

BATISTA MAV; BEZERRA NETO F; AMBRÓSIO MMQ; GUIMARÃES LMS; SARAIVA JPB; SILVA ML. 2013. Atributos microbiológicos do solo e produtividade de rabanete influenciados pelo uso de espécies espontâneas. Horticultura Brasileira 31:587594.

BARROTI G; NAHAS E. 2000. População microbiana total e solubilizadora de fosfato em solo submetido a diferentes sistemas de cultivo. Pesquisa Agropecuária Brasileira 35: 2043-2050.

BERTTIOL W; GHINI R. 2005. Solos supressivos
In: MICHERIFF SJ; ANDRADE DRGT; MENEZES M (eds). Ecologia e manejo supressivo de patógenos em solos tropicais. Pernambuco: UFRPE. 398p.

BEZERRA NETO F; GÓES SB; SÁ JR; LINHARE PCF; GÓES GB; MOREIRA JN. 2011. Desempenho agronômico da alface em diferentes quantidades e tempos de decomposição de jitirana verde. Revista Brasileira de Ciências Agrárias 6: 236-242.

CAO L; QIU Z; YOU J; TAN H; ZHOU S. 2004. Isolation and characterization of endophytic streptomyces strains from surface-sterilized tomato (Lycopersicon esculentum) roots. Letters in Applied Microbiology 39: 425- 430.

CASAGRANDE JC; ALLEONI LRF; CAMARGO OA; BORGES M. 2003 Adsorção de fosfato e sulfato em solos com cargas elétricas variáveis. Revista Brasileira Ciência do Solo 27: 51-59.

CAVALCANTI FJA. 1998. Recomendações de adubação para o estado de Pernambuco. Recife: IPA. 198p.

FAQUIN V; ANDRADE AT. 2004. Nutrição mineral e diagnose do estado nutricional das hortaliças. Lavras: UFLA/FAEPE. 88p.

FERREIRA DF. 2000. Sistema SISVAR para análises estatísticas: Manual de orientação. Lavras: UFLA/Departamento de Ciências Exatas. $37 \mathrm{p}$.

GAMA-RODRIGUES EF; BARROS NF; GAMA-RODRIGUES AC; SANTOS GA. 2005. Nitrogênio, carbono e atividade da biomassa microbiana do solo em plantações de eucalipto. Revista Brasileira de Ciência do Solo 1: 893-901.

GÓES SB; SÁ JR; DUDA GD; BEZERRA NETO F; SILVA ML; LINHARES PCF. 2014. Changes in the $\mathrm{pH}$ and macronutrients in soil fertilized with hairy woodrose in different amounts and times of incorporation. Revista Caatinga 27: 1-10.

GRAHAM MH; HAINES RJ. 2006. Organic matter status and the size, activity and metabolic diversity of the soil microbial community in the row and inter-row of sugar cane under burning a trash retention. Soil Biology \& Biochemistry 38: 21-31.

IBGE. Instituto Brasileiro de Geografia e Estatística. 2009. Censo Agropecuário de 2006. Rio de Janeiro: IBGE. 777p.

JANDEL SCIENTIFIC. 1991. Table Curve: curve fitting software. Corte Madera, CA: Jandel Scientific. 280p.
LINHARES PCF; PEREIRA MFS; ASSIS JP; BEZERRAAKH. 2012. Quantidades e tempos de decomposição da jitirana no desempenho agronômico do coentro. Ciência Rural 42: 243-248.

LINHARES PCF; SILVA ML; PEREIRA MFS; BRITO BF; FILHO ED. 2009. Velocidade de decomposição do mata-pasto no desempenho agronômico da rúcula (Eruca sativa) cv. Cultivada. Revista Verde 4: 106-112.

MATOS FAC; LOPES, HRD; DIAS RL; ALVES RT. Beterraba - Coleção passo a passo. Brasília: SEBRAE, 2012. 25 p. (Série Agricultura Familiar).

NOVAIS RF; ALVAREZ VH; BARROS NF; FONTES RL; CANTARUTTI RB; NEVES JCL. 2007. Fertilidade do solo. Sociedade Brasileira de Ciência do Solo, Viçosa-MG. $1017 \mathrm{p}$.

SCHIPPERS B; BAKKER AW; BAKKER HM. 1987. Interactions of deleterious and beneficial rhizosphere microorganisms and the effect of cropping practices. Annual Review Phytopathology 25: 339-358.

SILVA ML; BEZERRA NETO F; LINHARES PCF; BEZERRA AKH. 2013. Produção de cenoura fertilizada com flor-de-seda (Calotropis procera (Ait.) R.Br.). Revista Ciência Agronômica 44: 732-740.

SILVA AAS; CORREIA VR. 2014. Crotalaria juncea em substituição a adubação nitrogenada na cultura da beterraba. Jornada de Iniciação Científica e Extensão 5: 3259-3262.

SOUZAEGF; BARROS JÚNIOR AP; BEZERRA NETO F; SILVEIRA LM; LEAL YH; ALVES MJG. 2015. Rentabilidade da rúcula fertilizada com biomassa de flor-de-seda em função da época de cultivo. Revista Caatinga 28: 65-77.

TIVELLI SW; FACTOR TL; TERAMOTO JRS; FAHI EG; MORAES ARA; TRANI PE; MAY A. 2011. Beterraba, do plantio à comercialização. Série Tecnologia APTA. Boletim Técnico IAC, 210. Campinas: Instituto Agronômico. 45p.

TORRES JLR; PEREIRA MG. 2008. Dinâmica do potássio nos resíduos vegetais de plantas de cobertura no cerrado. Revista Brasileira de Ciência do Solo 32: 1609-1618.

TRANNIN ICB; SIQUEIRA JO; MOREIRA FMS. 2007. Características biológicas do solo indicadoras de qualidade após dois anos de aplicação de biossólido industrial e cultivo de milho. Revista Brasileira de Ciências do Solo 1: 1173-1184. 